\title{
PENGARUH PENAMBAHAN ABU TERBANG (Fly Ash) TERHADAP KUAT TEKAN PAVING BLOCK
}

\section{THE EFFECT OF FLY ASH ADDITION TO COMPRESSIVE STRENGTH OF PAVING BLOCK}

\author{
Anggi Harystama ${ }^{1}$, M. Agus Salim Al Fathoni ${ }^{2}$, Amris Azizi ${ }^{3}$ \\ ${ }^{123}$ Program Studi S1 Teknik Sipil, Fakultas Teknik dan Sains \\ Universitas Muhammadiyah Purwokerto
}

\section{Informasi Artikel \\ Dikirim, \\ Direvisi, \\ Diterima,}

\section{Korespondensi Penulis:}

Anggi Harystama Program Studi Teknik Sipil Universitas Muhammadiyah Purwokerto

JL. K.H. Ahmad Dahlan

Purwokerto, 53182

Email:

anggiharystama@gmail.com

\section{ABSTRAK}

Paving block merupakan produk bahan bangunan dari semen yang digunakan sebagai salah satu alternatif penutup atau pengerasan tanah.. Tujuan penelitian untuk mengetahui kuat tekan paving block dengan penambahan abu terbang (fly ash) dengan variasi campuran 5\%,10\%,15\%,20\% terhadap berat semen, penelitian ini merupakan penelitian eksperimen yang menggunakan benda uji berbentuk kubus dengan panjang $6 \mathrm{~cm}$ dan lebar $6 \mathrm{~cm}$ benda uji paving block dengan jumlah benda uji berjumlah 3 sampel setiap varisi. Pengujian kuat tekan paving block dilakukan pada umur 28 hari. Hasil penelitian ini menunjukan data sebagai berikut : a) kuat tekan rata-rata variasi fly ash $5 \%$ dengan kuat tekan 7,22 $\mathrm{MPa}$. b) kuat tekan rata-rata variasi fly ash $10 \%$ dengan kuat tekan 8,1 $\mathrm{MPa}$. c) kuat tekan rata-rata variasi fly ash $15 \%$ dengan kuat tekan $8,42 \mathrm{MPa}$. d) kuat tekan rata-rata variasi fly ash $20 \%$ dengan kuat tekan 9,34 $\mathrm{MPa}$.

Kata Kunci : Paving Block, Fly Ash, Kuat Tekan

\section{ABSTRACT}

The paving block is a building material product made from cement which is used as an alternative cover or to harden the soil. The purpose of this study was to examine the compressive strength of paving blocks with the addition of fly ash with a mixture variation of $5 \%, 10 \%, 15 \%, 20 \%$ on the weight of cement. This research was an experimental study using a cube-shaped specimen with a length of $6 \mathrm{~cm}$ and a width of 6 $\mathrm{cm}$ paving block specimens with the number of specimens totalling 3 samples per variant. Paving block compressive strength testing was conducted at day of 28 . The results of this study showed the following data: a) the average compressive strength of $5 \%$ fly ash variation with a compressive strength of $7.22 \mathrm{MPa} . b$ ) compressive strength average of $10 \%$ fly ash variation with $8.1 \mathrm{MPa}$ compressive strength. c) compressive strength average of $15 \%$ fly ash variation with $8.42 \mathrm{MPa}$ compressive strength. d) compressive strength average of $20 \%$ fly ash variation with $9.34 \mathrm{MPa}$ compressive strength.

Keyword : Paving Block, Fly Ash, Compressive Strength 


\section{PENDAHULUAN}

Dalam aplikasi dunia teknik sipil, paving block merupakan salah satu contoh produk yang digunakan pada perkerasan tanah. Paving block merupakan produk bahan bangunan dari semen yang digunakan sebagai salah satu alternatif penutup atau pengerasan tanah. Di antara berbagai macam alternatif penutup permukaan tanah, paving block lebih memiliki banyak variasi baik dari segi bentuk, ukuran, warna, corak dan tekstur permukaan, serta kekuatan.

Penggunaan paving block juga dapat divariasikan dengan jenis paving atau bahan bangunan penutup tanah lainnya. Paving block memiliki banyak keunggulan diantaranya adalah menjaga keseimbangan air tanah untuk menopang betonan / rumah diatasnya, berat paving block yang relatif lebih ringan dari betonan / aspal menjadikan satu penopang utama agar pondasi rumah tetap stabil, dan dapat menjadi serapan air yang baik di sekitar rumah sehingga menjamin ketersediaan air.

Penelitian ini mencoba memanfaatkan kondisi alam Indonesia maupun pemanfaatan bahan-bahan lokal yang memungkinkan dilaksanakannya pembuatan beton bermutu tinggi. Usaha penelitian perlu dilakukan untuk mendapatkan suatu alternatif baru dalam teknologi bahan, dengan menggunakan bahan yang seefisien mungkin yaitu dengan menambahkan abu terbang (fly ash) sebagai bahan tambah, sehingga abu terbang (fly ash) diharapkan dapat menghasilkan paving block dengan kuat tekan yang lebih tinggi dan ramah bagi lingkungan.

\section{METODE PENELITIAN}

Jenis penelitian metode yang digunakan dalam penelitian ini adalah metode eksperimen atau percobaan yang di lakukan di laboratorium untuk mengetahui hubungan yang terjadi dari variabel sebgai hasil percobaan. Penelitian ini menggunakan beberapa sempel dengan beberapa variasi penambahan abu terbang ( fly ash ) $5 \%$, $10 \%, 15 \%, 20 \%$ terhadap berat semen yang bertujuan untuk mengetahui berapa besar kuat tekan yang dihasilkan dan mencari kuat tekan optimum dari sampel tersebut dengan menggunakan perbandangan berat bahan adukan $1: 4$.

Varaibel bebas dalam penelitian ini adalah penambahan abu terbang ( fly ash ) sebagai bahan tambahan untuk pembuatan paving block. Sedangkan untuk variable terikat pada penelitian ini adalah kuat tekan paving block. Untuk mengendalikan kedua variabel tersebut, diperlukan variabel yang di buat konstan sehingga pengaruh variabel bebas terhadap variabel terikat tidak di pengaruhi oleh faktor luar yang tidakk di teliti. Untuk variabel pengendali yang di buat konstan pada penelitian ini yaitu jumlah berat agregat dalam campuran adukan paving block. Jenis dan merek semen, jenis agregat, dan perawatan.

\section{HASIL DAN PEMBAHASAN}

\subsection{Lokasi dan Waktu Penelitian}

Penelitian dilakukan di Laboratorium Teknologi Bahan Fakultas Teknik dan Sains Universitas Muhammadiyah Purwokerto.

\subsection{Hasil Uji Agregat Halus}

Pengujian terhadap agregat halus yang berupa pasir Sungai Serayu dalam penelitian ini meliputi :

1. Pemeriksaan kadar lumpur pada pasir.

2. Pemeriksaan berat jenis pasir.

Adapun hasil pengujian agregat halus yaitu sebagai berikut :.

\section{Pemeriksaan Kadar Lumpur Pada Pasir.}

Tabel 1. Hasil Pemeriksaan Kadar Lumpur

\begin{tabular}{clcc}
\hline \multirow{2}{*}{ No. } & \multicolumn{1}{c}{ Uraian } & Sampel (1) & Sampel (2) \\
\cline { 2 - 4 } & Berat Awal (pasir kering oven, W1) & 500 & (gram) \\
\hline 1 & Berat Akhir (pasir kering oven, W2) & 487 & 500 \\
Kandungan Lumpur & 2,6 & 491 \\
KL = (W1-W2) / W1 x 100 (\%) & \multicolumn{2}{c}{2,2} \\
Kandungan Lumpu rata - rata : (\%) & \multicolumn{3}{c}{} \\
\hline Sumber : Penelitian 2019
\end{tabular}

Kadar lumpur rata rata diperoleh sebesar 2,2\%. Hasil ini menunjukan bahwa agregat halus yang di pakai memenuhi syarat sebagai bahan pengesi beton sesuai dengan SK SNI S-04-1998-F,1989. Nilai kadar lumpur 
maksimum yang diizininkan sebesar $5 \%$.

2. Pemeriksaan Berat Jenis Pasir.

Tabel 2. Hasil Pemeriksaan Berat Jenis Pasir

\begin{tabular}{|c|c|c|c|c|}
\hline \multirow{2}{*}{ No. } & \multirow{2}{*}{\multicolumn{2}{|c|}{ Uraian }} & Sampel (1) & Sampel (2) \\
\hline & & & (gram) & (gram) \\
\hline 1 & Berat pasir SSD & (A) & 500 & 500 \\
\hline 2 & Berat tabung + air & (B) & 662 & 662 \\
\hline 3 & Berat tabung + pasir + air & (C) & 975 & 977 \\
\hline 4 & Berat pasir kering oven & (D) & 456 & 455 \\
\hline \multicolumn{3}{|c|}{ Berat jenis atas dasar kering oven } & 2,44 & 2,43 \\
\hline \multicolumn{2}{|c|}{$=\mathrm{A} / \mathrm{B}+\mathrm{A}-\mathrm{C})$} & & 2,67 & 2,7 \\
\hline \multicolumn{3}{|c|}{ Berat Jenis Semu } & 3,19 & 3,23 \\
\hline \multicolumn{3}{|c|}{ Penyerapan } & $9,65 \%$ & $9,90 \%$ \\
\hline
\end{tabular}

\section{Komposisi Matrial Pada Tiap Variasi}

Tabel 3. Komposisi Material Pada Tiap Variasi Tanpa Campuran Fly Ash

\begin{tabular}{cccc}
\hline \multirow{2}{*}{ No. } & \multirow{2}{*}{ Variasi } & \multicolumn{2}{c}{ Komposisi Agregat } \\
\cline { 2 - 4 } & $0 \%$ & 1 & Semen $(\mathrm{Kg})$ \\
\hline 1 & &
\end{tabular}

Table 4. Komposisi Material Pada Tiap Variasi Dengan Campuran Fly Ash

\begin{tabular}{ccccc}
\hline & & \multicolumn{3}{c}{ Komposisi Agregat } \\
\cline { 3 - 5 } No. & Variasi & Semen ( Kg) & Pasir ( Kg ) & Fly Ash ( Kg ) \\
\hline 1 & $5 \%$ & 1 & 4 & 0,050 \\
2 & $10 \%$ & 1 & 4 & 0,100 \\
3 & $15 \%$ & 1 & 4 & 0,150 \\
4 & $20 \%$ & 1 & 4 & 0,200
\end{tabular}

\subsection{Pembuatan benda uji}

Dalam pembuatan benda uji,ada beberapa tahap yang harus dilakukan.

Adapun tahap - tahap tersebut adalah sebagai berikut :

a. Pengadukan paving block

Komposisi matrial dasar pembentuk paving block diaduk dalam suatu wadah (concretemixer) untuk memperoleh campuran yang merata.

b. Penuangan adukan paving block

Setelah adukan paving block tercampur dengan rata, kemudian dituangkan ke dalam cetakan setinggi cetakan.

c. Pemadatan adukan paving block

Setelah cetakan terisi penuh dan diratakan, kemudian dipadatkan dengan cara dipukul menggunakan plat besi.

\subsection{Perawatan benda uji}

Perawatan benda uji dengan cara pengeringan secara priodik setiap harinya sampai benda uji mencapai umur 28 hari dan disirami.

\subsection{Hasil Uji Kuat Tekan (Compressive Strength) Paving Block}

Hasil pengukuran kuat tekan dengan variasi campuran semen, fly ash dan pasir yang telah dibuat mengasilkan data kuat tekan rata-rata dari setiap sempel seperti diperlihatkan pada table dibawah ini.

Pengaruh Penambahan Abu Terbang (Fly Ash) Terhadap Kuat Tekan Paving Block (Anggi Harystama) 
Rumus Penghitungan Kuat Tekan :

$>$ Berat Isi $\left(\mathrm{kg} / \mathrm{cm}^{3}\right)$

$$
\frac{\text { Berat }}{\text { volume kubus } \mathrm{s}^{3}} \times 1000
$$

Kuat Tekan (Ton)

$$
\frac{\text { Berat }}{1 \mathrm{KN}=102 \mathrm{~kg} / \mathrm{cm}^{2}} \times 1000
$$

Kuat Tekan $\left(\mathrm{kg} / \mathrm{cm}^{2}\right)$

$$
\left(\frac{\text { Kuat Tekan (ton) }}{\text { Luas Bidang }}\right) \times 1000: 0,83
$$

Tabel 5. Hasil Kuat Tekan Paving Block Dengan Penambahan $0 \%$ Fly Ash

\begin{tabular}{lccc}
\hline \multicolumn{1}{c}{ Sampel } & 1 & 2 & 3 \\
\hline Tanggal Pembuatan & 28 Juni 2019 & 28 Juni 2019 & 28 Juni 2019 \\
Pembacaan (KN) & 35 & 32 & 30 \\
Berat (gr) & 611 & 575 & 555 \\
Luas Bidang $\left(\mathrm{cm}^{2}\right)$ & 36 & 36 & 36 \\
Tanggal Uji & 29 Juli 2019 & 29 Juli 2019 & 29 Juli 2019 \\
Umur (hari) & 28 & 28 & 28 \\
Kuat Tekan Paving Block (Mpa) & 9,72 & 8,89 & 8,34 \\
\hline Sumber : Penelitian 2019 & & &
\end{tabular}

$$
\text { Kuat tekan rata-rata }: \frac{9,72+8,89+8,34}{3}=8,98 \mathrm{Mpa}
$$

Tabel 6. Hasil Kuat Tekan Paving Block Dengan Penambahan $5 \%$ Fly Ash

\begin{tabular}{lccc}
\hline \multicolumn{1}{c}{ Sampel } & 1 & 2 & 3 \\
\hline Tanggal Pembuatan & 28 Juni 2019 & 28 Juni 2019 & 28 Juni 2019 \\
Pembacaan $(\mathrm{KN})$ & 27 & 25 & 26 \\
Berat $(\mathrm{gr})$ & 519 & 519 & 515 \\
Luas Bidang $\left(\mathrm{cm}^{2}\right)$ & 36 & 36 & 36 \\
Tanggal Uji & 29 Juli 2019 & 29 Juli 2019 & 29 Juli 2019 \\
Umur (hari) & 28 & 28 & 28 \\
Kuat Tekan Paving Block (Mpa) & 7,50 & 6,94 & 7,22
\end{tabular}
Sumber : Penelitian 2019

Kuat tekan rata-rata $: \frac{7,50+6,94+7,22}{3}=7,22 \mathrm{Mpa}$

Tabel 7. Hasil Kuat Tekan Paving Block Dengan Penambahan $10 \%$ Fly Ash

\begin{tabular}{lccc}
\hline \multicolumn{1}{c}{ Sampel } & 1 & 2 & 3 \\
\hline Tanggal Pembuatan & 28 Juni 2019 & 28 Juni 2019 & 28 Juli 2019 \\
Pembacaan (KN) & 31 & 29 & 27 \\
Berat (gr) & 624 & 561 & 562 \\
Luas Bidang $\left(\mathrm{cm}^{2}\right)$ & 36 & 36 & 36 \\
Tanggal Uji & 29 Juli 2019 & 29 Juli 2019 & 29 Juli 2019 \\
Umur (hari) & 28 & 28 & 28 \\
Kuat Tekan Paving Block (Mpa) & 8,61 & 8.1 & 7,50 \\
\hline
\end{tabular}

Sumber : Penelitian 2019

$$
\text { Kuat tekan rata-rata }: \frac{8,61+8,1+7,50}{3}=8,1 \mathrm{Mpa}
$$

Tabel 8. Hasil Kuat Tekan Paving Block Dengan Penambahan $15 \%$ Fly Ash

\begin{tabular}{lccc}
\hline \multicolumn{1}{c}{ Sampel } & 1 & 2 & 3 \\
\hline Tanggal Pembuatan & 28 Juni 2019 & 28 Juni 2019 & 28 Juni 2019 \\
Pembacaan $(\mathrm{KN})$ & 33 & 30 & 28 \\
\hline
\end{tabular}




\begin{tabular}{lccc}
\hline Berat $(\mathrm{gr})$ & 534 & 560 & 547 \\
Luas Bidang $\left(\mathrm{cm}^{2}\right)$ & 36 & 36 & 36 \\
Tanggal Uji & 29 Juli 2019 & 29 Juli 2019 & 29 Juli 2019 \\
\hline Sumber : Penelitian 2019 & &
\end{tabular}

Kuat tekan rata-rata $: \frac{9,16+8,33+7,77}{3}=8,42 \mathrm{Mpa}$

Tabel 9. Hasil Kuat Tekan Paving Block Dengan Penambahan 20 \% Fly Ash

\begin{tabular}{lccc}
\hline \multicolumn{1}{c}{ Sampel } & 1 & 2 & 3 \\
\hline Tanggal Pembuatan & 28 Juni 2019 & 28 Juni 2019 & 28 Juni 2019 \\
Pembacaan (KN) & 35 & 33 & 33 \\
Berat (gr) & 615 & 597 & 583 \\
Luas Bidang $\left(\mathrm{cm}^{2}\right)$ & 36 & 36 & 36 \\
Tanggal Uji & 29 Juli 2019 & 29 Juli 2019 & 29 Juli 2019 \\
Umur (hari) & 28 & 28 & 28 \\
Kuat Tekan Paving Block (Mpa) & 9,72 & 9,16 & 9,16
\end{tabular}

Kuat tekan rata-rata $: \frac{9,72+9,16+9,16}{3}=9,34 \mathrm{Mpa}$

KUAT TEKAN TERHADAP PENAMBAHAN FLY ASH

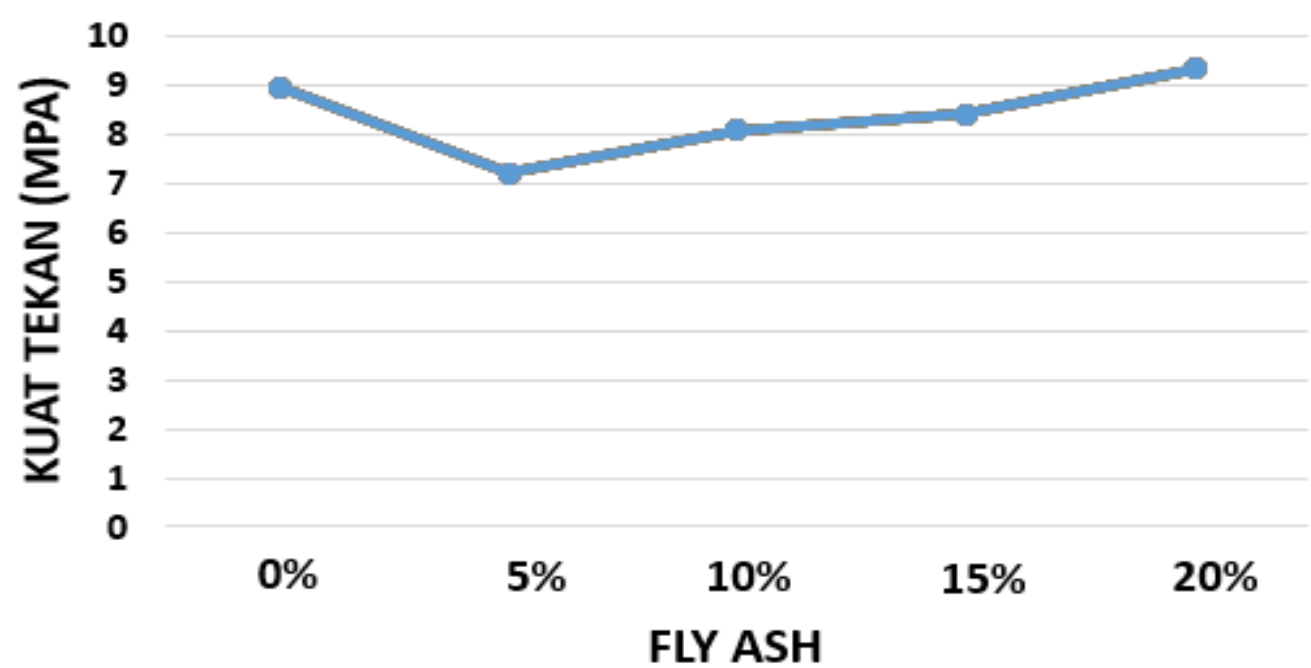

Gambar 4.1 Hasil Uji Kuat Tekan Paving Block Sumber : Penelitian 2019

Nilai kuat tekan rata-rata tertinggi dimiliki oleh sempel yang mempunyai perbandingan semen pasir dan fly ash (20\%) dengan nilai kuat tekan sebesar 9,34 Mpa, semakin banyak campuran komposisi fly ash dalam pembuatan paving block ternyata memberikan peningkatan terhadap sifat - sifat fisik dan mekanik paving block.

Berdasarkan nilai kuat tekan rata-rata maksimum yang diperolehkan pada peraturan (SNI 0691 - 1996) pada tabel, maka paving block hasil penelitian dapat di kelompokan sebagi berikut :

A. Sampel dengan penambahan $0 \%$ termasuk dalam mutu D untuk taman dll, dengan nilai kuat tekan sebesar $8,98 \mathrm{Mpa}$

B. Sampel dengan penambahan fly ash $5 \%$ termasuk dalam mutu D untuk taman dll, dengan nilai kuat tekan sebesar 7,22 Mpa

C. Sampel dengan penambahan fly ash $10 \%$ termasuk kedalam mutu D untuk taman dll, dengan nilai kuat tekan sebesar 8,1 Mpa

D. Sampel dengan penambahan fly ash $15 \%$ termasuk kedalam mutu D untuk taman dll, dengan nilai kuat tekan sebesar 8,42 Mpa

E. Sampel dengan penambahan fly ash $20 \%$ termasuk kedalam mutu D untuk taman dll, dengan nilai kuat tekan sebesar 9,34 Mpa 


\section{KESIMPULAN}

Berdasarkan dari pengujian paving block dengan penambahan fly ash sebesar 5\%,10\%, 15\%, $20 \%$ dari berat semen pada 4 (empat) jenis komposisi campuran yang dicoba dapat diambil kesimpulan Hasil kuat tekan rata-rata paving blok variasi $5 \%, 10 \%, 15 \%, 20 \%$ fly ash variasi $1 \mathrm{~kg}$ semen : $4 \mathrm{~kg}$ pasir : $5 \%$ fly ash kuat tekan rata-rata 7,22 MPa, variasi $1 \mathrm{~kg}$ semen : $4 \mathrm{~kg}$ pasir : $10 \%$ fly ash kuat tekan rata-rata 8,1 MPa, variasi $1 \mathrm{~kg}$ semen : $4 \mathrm{~kg}$ pasir : $15 \%$ fly ash kuat tekan rata-rata $4,22 \mathrm{MPa}$, variasi $1 \mathrm{~kg}$ semen : $4 \mathrm{~kg}$ pasir : $20 \%$ fly ash kuat tekan rata-rata 9,34 MPa. ash dan telah memenuhi mutu paving block D menurut ketentuan SNI 03-06911996. Penentuan variasi terbaik adalah berdasarkan atas hasil pengujian kuat tekan paving block adalah pada variasi $1 \mathrm{~kg}$ semen : $4 \mathrm{~kg}$ pasir : 20\% fly ash dengan rata-rata 9,34 MPa dan telah memenuhi mutu paving block D menurut ketentuan SNI 03-0691-1996.

\section{DAFTAR PUSTAKA}

[1] Anggodo (2014) Pengaruh Penggunaan Abu Batu Bara (Fly Ash) Terhadap Kuat Tekan Paving Block. Skripsi . samarinda. Universitas 17 Agustus 1945

[2] Arifin (2017). Kuat Tekan Paving Block Segi Enam Dengan Variasi Jumlah Semen Dengan Bahan Tambah Kalsit Secara Konvensional. Skripsi. Surakarta. Universitas Muhammadiyah Surakarta.

[3] Mulyati dan Maliar ( 2015 ) Pengaruh Penggunaan Fly Ash Sebagai Pengganti Agregat Terhadap Kuat Tekan Paving Block. Jurnal Momentum. Vol.17 No.1. Februari 2015. ISSN : 1693-752X.

[4] Witarso dan Lasino (2015) Pengaruh Penambahan Abu Terbang Pada Paving Block Berbahan Baku Taling Asbuton. Jurnal jalan-jembatan. Volume 32.

[5] Mulyati dan Maliar ( 2015 ) Pengaruh Penggunaan Fly Ash Sebagai Pengganti Agregat Terhadap Kuat Tekan Paving Block. Jurnal Momentum. Vol.17 No.1. Februari 2015. ISSN : 1693-752X.

[6] Nurzal and Nursyuhada (2017) The Effect of Coloring and Compacting Pressure Paving Block by Adding 5 Wt.\% Fly Ash in The Compressive Strength. Skripsi. Padang. Universitas Teknologi Padang.

[7] Surat Keputusan Standar Nasional Indonesia SNI 03-0691-1996 (Persyaratan Mutu dan Cara Uji Paving Block).

[8] Surat Keputusan Standar Nasional Indonesia SNI 03-1969-2008 (Uji Berat Jenis dan Penyerapan air Agregat).

[9] Surat Keputusan Standar Nasional Indonesia SNI 03-1968-1990 (Uji Gradasi).

[10] Surat Keputusan Standar Nasional Indonesia SNI 03 - 2834 - 2000 (Gradasi Agregat Halus).

[11] Surat Keputusan Standar Nasional Indonesia SNI S-04-1989-F (Spesifikasi Bahan Bangunan Bagian A Bahan Bangunan Bukan Logam).

[12] Surat Keputusan Standar Nasional Indonesia SNI 2460-2014 (Spesifikasi Abu Terbang Batu Bara Dan Pozolan Alam Mentah Atau Yang Telah Di Kalsinasi Untuk Digunakan Dalam Beton).

[13] Thaarrini and Venkatasubramani (2017) Feasibility Studies on Compressive Strength of Ground Coal Ash Geopolymer Mortar. Skripsi . Coimbatore. University Sri Ramakrishna Institute of Technology 